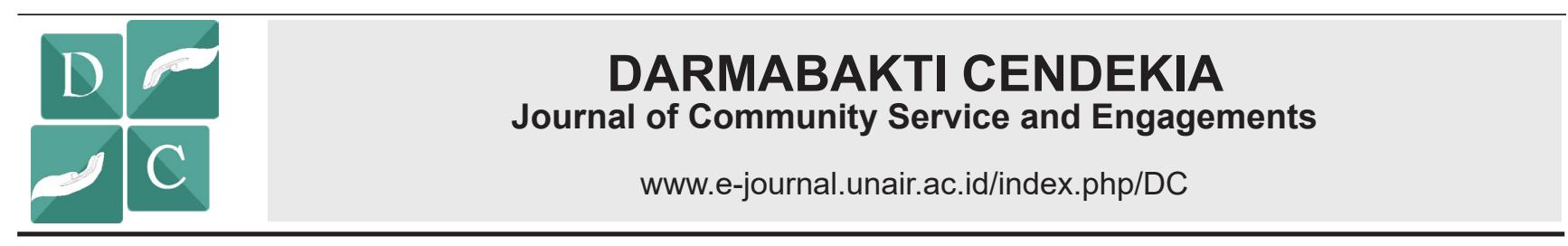

\section{INTEGRATION OF HEALTH SECTOR IN EFFORTS TO IMPROVE THE HEALTH OF OLDER PEOPLE IN RW VII JAGIR SURABAYA}

\author{
INTEGRASI BIDANG KESEHATAN DALAM UPAYA \\ MENINGKATKAN KESEHATAN MASYARAKAT LANJUT USIA DI \\ RW VII KELURAHAN JAGIR SURABAYA
}

Ario Imandiri ${ }^{1^{*}}$, Eny Inayati², Retno Sri Wahjuni ${ }^{3}$

${ }^{1}$ Traditional Medicine, Department of Health, Faculty of Vocational Studies, Universitas Airlangga, Surabaya-Indonesia

${ }^{2}$ Dental Technique, Department of Health, Faculty of Vocational Studies, Universitas Airlangga, Surabaya-Indonesia

${ }^{3}$ Veterinary Paramedics, Department of Health, Faculty of Vocational Studies, Universitas Airlangga, Surabaya-Indonesia
Scope:

Health

\section{A B S T R A C T}

Background: The older people get, the more elderly people who experience health complaints. The elderly morbidity rate in 2014 was 25.05 percent, meaning that around one in four elderly people had experienced pain in the past month. Purpose: Providing guidance and knowledge to improve the health of the elderly community in RW VII Jagir. Method: Coaching is carried out by using a tutorial and visualization method using LCD. The material provided includes the processing of healthy foods, the introduction of traditional medicine, independent acupressure, healthy work attitudes in the household, dental and oral health, and medical check up. Results: The people who attended this activity were 65 people, according to the expected target. The community welcomed with enthusiasm, as evidenced by a large number of people present and the high level of community participation until the end of the event. In addition, there was also an increase in the mean value of the questionnaire before and after the activity, from 15.62 to 36.14. The results of 55 participants who did blood pressure checks, 28 people had normal blood pressure and 27 people experienced blood pressure that was more than normal. Likewise, the results of blood sugar tests when, of the 55 people who took blood sugar at their time, 43 had normal blood sugar levels or less than $200 \mathrm{mg} / \mathrm{dL}$; and 12 people have blood sugar levels that are above normal or $>200 \mathrm{mg} / \mathrm{dL}$. Conclusion: Community service activities are very useful for the elderly and also able to increase the knowledge of the elderly.

\begin{abstract}
A B S T R A K
Latar belakang: Semakin bertambah tua umurnya, maka lansia yang mengalami keluhan kesehatan akan semakin banyak. Angka kesakitan lansia tahun 2014 sebesar 25,05 persen, berarti bahwa sekitar satu dari empat lansia pernah mengalami sakit dalam satu bulan terakhir. Tujuan: Memberikan pembinaan dan pengetahuan untuk meningkatkan kesehatan masyarakat lansia di RW VII Jagir. Metode: Pembinaan dilaksanakan menggunakan metode tutorial dan visualisasi menggunakan LCD. Materi yang diberikan meliputi senam lansia, demo pengolahan makanan sehat, pengenalan obat tradisional, akupresur mandiri, sikap kerja yang sehat pada rumah tangga, kesehatan gigi dan mulut, serta pemeriksaan kesehatan. Hasil: Masyarakat yang hadir dalam kegiatan ini adalah 65 orang, sesuai dengan target yang diharapkan. Masyarakat menyambut dengan antusias, terbukti dengan banyaknya jumlah masyarakat yang hadir serta tingginya partisipasi masyarakat hingga akhir acara. Selain itu, juga terjadi peningkatan rerata nilai kuesioner sebelum dan setelah kegiatan, dari 15,62 menjadi 36,14. Hasil dari 55 orang peserta yang melakukan pemeriksaan tekanan darah, 28 orang memiliki tekanan darah yang normal dan 27 orang mengalami tekanan darah yang lebih di atas normal. Demikian pula dengan hasil pemeriksaan gula darah sewaktu, dari 55 orang yang memeriksakan gula darah sewaktunya, 43 orang memiliki kadar gula darah normal atau kurang dari $200 \mathrm{mg} / \mathrm{dL}$; dan 12 orang memiliki kadar gula darah sewaktu yang lebih di atas normal atau $>200 \mathrm{mg} / \mathrm{dL}$. Kesimpulan: Kegiatan pengabdian masyarakat ini sangat bermanfaat bagi lansia serta mampu meningkatkan pengetahuan lansia.
\end{abstract}

A R T I C LE IN FO

Recieved 28 September 2019 Accepted 18 October 2019 Online 20 December 2019

*Correspondence (Korespondensi): Ario Imandiri

E-mail:

ario.imandiri@vokasi.unair.ac.id

Keywords:

Health; Quality of life; Elderly

Kata kunci:

Kesehatan; Kualitas Hidup; Lansia

Darmabakti Cendekia: Journal of Community Service and Engagements p-ISSN: 2657-201X; e-ISSN: 2657-1099 DOI: 10.20473/dc.v1i2.2019.56-59

Open access under Creative Commons Attribution-Non Comercial-Share A like 4.0 International License 


\section{PENDAHULUAN}

Kota Surabaya termasuk kota yang memiliki persentase pertumbuhan lanjut usia (Lansia) cukup tinggi. Menurut data Kantor Catatan Sipil Kota Surabaya, jumlah lanjut usia 60+ Kota Surabaya pada tahun 2015 mencapai 296.190 jiwa atau $10.1 \%$. Hal ini dapat terjadi karena, salah satunya, dipengaruhi oleh semakin meningkatnya usia harapan hidup, di mana usia harapan hidup kota Surabaya mencapai 72.13 tahun.

Dalam aspek kesehatan diketahui semakin bertambah tua umurnya, maka lansia yang mengalami keluhan kesehatan akan semakin banyak. Sebanyak 37,11 persen penduduk pra lansia (45-59 tahun) pernah mengalami keluhan kesehatan dalam sebulan terakhir, sementara lansia muda (6069 tahun) sebesar 48,39 persen, lansia madya (7079 tahun) sebesar 57,65 persen, dan lansiatua (8089 tahun) sebesar 64,01 persen yang mengeluhkan kondisi kesehatannya. Selanjutnya, ditilik dari angka kesakitan (morbidity rates) lansia yaitu terganggunya kegiatan sehari-hari sebagai akibat dari keluhan kesehatan yang dideritanya. Angka kesakitan lansia tahun 2014 sebesar 25,05 persen, berarti bahwa sekitar satu dari empat lansia pernah mengalami sakit dalam satu bulan terakhir. Dengan semakin banyaknya keluhan kesehatan pada lansia, maka akan mengurangi kualitas hidupnya.

Pelayanan kesehatan harus diberikan secara maksimal untuk memenuhi hak lansia dalam meningkatkan kesejahteraan sosialnya, sehingga dapat memelihara dan meningkatkan kondisi fisik, mental, dan sosialnya supaya dapat berfungsi secara wajar. Sebanyak 59,24 persen lansia dengan keluhan kesehatan masih mengobati penyakitnya sendiri, baik menggunakan obat modern $(66,01$ persen), obat tradisional (11,60 persen), maupun kombinasi kedua obat tersebut (21,20 persen). Lansia yang mengatasi keluhan kesehatannya dengan cara berobat jalan sebesar 51,24 persen. Terbanyak mereka berobat jalan di praktek tenaga kesehatan (33,71 persen), praktek dokter (31,70 persen), dan puskesmas (27,05 persen).

Undang-undang Nomor 13 Tahun 1998 tentang Kesejahteraan Lanjut Usia menjelaskan bahwa pelayanan kesehatan harus diberikan sebagai salah satu upaya untuk memenuhi hak lansia dalam meningkatkan kesejahteraan sosialnya. Pelayanan kesehatan yang dimaksud adalah dalam rangka memelihara dan meningkatkan derajat kesehatan dan kemampuan penduduk lansia agar kondisi fisik, mental, dan sosialnya dapat berfungsi secara wajar. Pelayanan kesehatan bagi lansia termasuk penyuluhan dan penyebarluasan informasi kesehatan, upaya penyembuhan (kuratif), yang diperluas pada bidang pelayanan geriatrik/ gerontologik, serta pengembangan lembaga perawatan lansia yang menderita penyakit kronis dan atau penyakit terminal. Upaya pemerintah yang telah dilakukan antara lain pendirian home care bagi lansia berkebutuhan khusus, program usaha ekonomi produktif, serta Posyandu Lansia. Kegiatan yang dilaksanakan melalui posyandu lansia di antaranya adalah pemeriksaan kesehatan, pemberian makanan tambahan, dan senam lansia.

Berbagai upaya dilakukan penduduk untuk menjaga kesehatan lansia, baik oleh lansia yang sakit secara mandiri maupun oleh keluarganya yang masih sehat. Upaya menjaga kesehatan yang dapat dilakukan di antaranya adalah dengan berobat sendiri, berobat jalan, maupun rawat inap. Berobat sendiri merupakan upaya mengobati penyakit atas inisiatif sendiri, berdasarkan pengetahuan kesehatan yang dimilikinya secara mandiri. Berobat jalan adalah melakukan konsultasi kesehatan kepada tenaga ahli kesehatan yang dipercaya, dengan cara mendatangi tempat pelayanan kesehatan modern maupun tradisional tanpa menginap, termasuk mendatangkan petugas kesehatan ke rumah. Adapun rawat inap adalah proses penyembuhan penyakit yang dilakukan di fasilitas kesehatan yang mendukung, dibawah pendampingan dan pengawasan petugas kesehatan yang kompeten.

Berdasar data BPS tahun 2014, separoh lebih lansia menangani keluhan kesehatannya dengan mengobati sendiri. Menurut jenis pengobatannya, sebagian besar lansia mengobati sendiri menggunakan obat modern (66,01 persen). Hanya 11,60 persen lansia yang mengobati sendiri menggunakan pengobatan tradisional, sementara sebesar 21,20 persen lansia sakit yang mencampurkan pengobatan modern dengan tradisional untuk mengatasi keluhan kesehatan yang diderita.

\section{METODE}

Kegiatan pengabdian yang dilakukan antara lain pembinaan, pelatihan dan pemeriksaan kesehatan. Pembinaan dilaksanakan dengan mengundang anggota kelompok lansia di Kota Surabaya dengan menggunakan metode tutorial dan visualisasi menggunakan LCD. Adapun materi yang diberikan meliputi pengolahan makanan sehat, pengenalan obat tradisional, akupresur mandiri dan sikap kerja yang sehat pada rumah tangga. Dalam upaya meningkatkan pengetahuan masyarakat maka akan dilakukan pelatihan bagi masyarakat yaitu demo pembuatan makanan sehat dan senam lansia. Untuk mengetahui kondisi kesehatan masyarakat, dilakukan pemeriksaan tekanan darah, pemeriksaan darah sederhana.

Dalam pelayanan kesehatan yang dilakukan tim pengusul, kelompok masyarakat berpartisipasi 
dalam hal penyediaan tempat. Selain itu, diharapkan kelompok masyarakat tersebut dapat memberikan evaluasi pelaksanaan pelayanan kesehatan sebagai masukan untuk tim pengusul. Untuk efektifitas pelakasaan kegiatan, sasaran program ini adalah kelompok lansia di wilayah RW VII Kelurahan Jagir Kecamatan Wonokromo Kota Surabaya, Jawa Timur.

Evaluasi yang dilakukan untuk mengetahui keberhasilan peningkatan pengetahuan para lansia setelah diberikan pembinaan dan pelatihan pada kegiatan ini adalah dengan menggunakan kuesioner.

\section{HASIL DAN PEMBAHASAN}

Kegiatan ini dilaksanakan pada 21 September 2019 dimulai pukul 05.30 WIB hingga 11.00 WIB dan dilaksanakan di Jalan Gembili Gang 1 No. 41 RW VII Kelurahan Jagir Kota Surabaya. Partisipan yang hadir dalam acara ini adalah perwakilan dosen dan perwakilan mahasiswa dari Program Studi D-III / D-IV Pengobat Tradisional. D-III / D-IV Fisioterapi, D-IV Teknologi Radiologi Pencitraan, D-III Teknik Gigi, D-III Teknologi Laboratorium Medis, D-III Keselamatan dan Kesehatan Kerja, serta D-III Paramedik Veteriner, Departemen Kesehatan Fakultas Vokasi Universitas Airlangga. Turut hadir undangan yakni Ketua RW VII Kelurahan Jagir Kota Surabaya, 65 orang Lansia RT 01-04 RW VII Kelurahan Jagir Kota Surabaya, Instruktur senam fisioterapi dan Ketua Departemen Kesehatan Fakultas Vokasi Universitas Airlangga.

Kegiatan pengabdian masyarakat ini dibagi menjadi lima bentuk kegiatan sesuai bidang kesehatan yang dinaungi oleh Departemen Kesehatan Fakultas Vokasi Universitas Airlangga. Kegiatan pertama dikoordinir oleh dr. Arni selaku perwakilan dosen dari Program Studi D-III/D-IV Fisioterapi dengan melakukan senam rematik untuk lansia dan dipandu oleh instruktur senam dari Program Studi D-III/D-IV Fisioterapi. Setelah pelaksanaan senam bersama Kelompok Lansia RW VII Kelurahan Jagir Kota Surabaya, dilanjutkan dengan istirahat dan sarapan bersama. Kegiatan kedua dilaksanakan sosialisasi tentang asuhan mandiri Tanaman Obat Keluarga (TOGA), bagaimana mengolah TOGA menjadi jamu sebagai salah satu pengobatan tradisional. Masyarakat lansia juga menikmati hidangan minuman jamu yang merupakan produk Program Studi D-III Pengobat Tradisional. Tidak hanya tentang tentang TOGA, pada kegiatan kedua ini, Ibu Maya Septriana, selaku KPS D-III Pengobat Tradisional memberikan penyuluhan mengenai Akupresur untuk penderita hipertensi sekaligus simulasi terapi pijat yang boleh dilakukan secara mandiri oleh masyarakat pada beberapa titik bagian tubuh.

Kegiatan ketiga dilaksanakan sosialisasi tentang bagaimana cara perawatan gigi tiruan atau gigi palsu oleh drg. Okti selaku perwakilan dosen Program Studi D-III Teknologi Gigi. Kemudian dilanjutkan dengan kegiatan keempat yaitu sosialisasi tentang cara melakukan aktivitas rumah tangga dengan postur yang benar sehingga tidak menyebabkan risiko gangguan nyeri pada otot. Sosialisasi ini disampaikan oleh dr. Erwin Dyah Nawawinetu selaku KPS D-III Keselamatan dan Kesehatan Kerja. Kegiatan selanjutnya adalah penyuluhan tentang pemilihan daging ayam yang sehat sekaligus demo memasak Sup Sehat metode Slow Cooking dengan bahan daging ayam kampung. Kegiatan tersebut dipandu oleh drh. Herinda selaku perwakilan dosen Program Studi D-III Paramedik Veteriner Kegiatan pengabdian masyarakat ini ditutup dengan pemeriksaan kesehatan yang dilakukan oleh perwakilan dosen dan mahasiswa dosen Program Studi D-III Teknologi Laboratorium Medis, D-III/D-IV Pengobat Tradisional, dan D-III Keselamatan dan Kesehatan Kerja. Pemeriksaan kesehatan yang dilakukan meliputi pengukuran tekanan darah, rapid test pengecekan gula darah acak dan asam urat. Hasil pemeriksaan disampaikan langsung kepada masyrakat sekaligus dengan pemberian konseling gaya hidup sehat. Kelompok Lansia RW VII Kelurahan Jagir Kota Surabaya sangat antusias mengikuti serangkaian acara sejak awal hingga akhir acara.

Ketua RW VII selaku perwakilan masyarakat menyampaikan rasa terimakasih dan apresiasi yang sebesar-besarnya kepada dosen maupun mahasiswa Departemen Kesehatan Fakultas Vokasi Universitas Airlangga. Beliau menambahkan kegiatan pengabdian masyarakat dengan lintas bidang kesehatan semacam ini diharapkan dapat membantu pemerintah Kota Surabaya dalam upaya meningkatkan kesehatan masyarakat khususnya kelompok lansia. Untuk itu, kerjasama yang telah terjalin agar tetap dipertahankan dan jika perlu terus ditingkatkan dimasa yang akan datang.

Untuk menilai keberhasilan peningkatan pengetahuan para lansia setelah diberikan pembinaan dan pelatihan pada kegiatan ini adalah dengan menggunakan kuesioner. Kuesioner terdiri dari 10 soal yang mudah dipahami lansia, yaitu terkait pemahaman mereka tentang topik materi yang diberikan. Peserta diminta memberi nilai dengan rentang 1 hingga 4; dimana 1 adalah sangat tidak paham, 2 adalah tidak paham, 3 adalah paham dan 4 adalah sangat paham. Nilai terendah pada kuesioner ini adalah 10 dan nilai tertingginya adalah 40. Kuesioner diisi pada saat sebelum dan setelah kegiatan dilaksanakan. Adapun hasil dari penilaian tersebut adalah rerata nilai kuesioner sebelum pembinaan adalah 15,62 kemudian reratanya naik 
menjadi 36,14 setelah pembinaan. Kenaikan rerata nilai antara sebelum dan setelah pembinaan adalah sebesar 20,52. Kenaikan rerata nilai ini sangat baik, menunjukkan bahwasannya pembinaan yang diberikan dapat memberikan wawasan baru serta meningkatkan pemahaman masyarakat terkait topik yang diberikan.

Hasil pemeriksaan tekanan darah ditunjukkan pada Tabel 1. Data tersebut menunjukkan bahwa dari 55 orang peserta yang melakukan pemeriksaan tekanan darah, 28 orang memiliki tekanan darah yang normal dan 27 orang mengalami tekanan darah yang lebih di atas normal. Dari 27 orang tersebut, 17 orang masuk dalam klasifikasi hipertensi derajat 1; 9 orang masuk dalam klasifikasi hipertensi derajat 2; dan 1 orang masuk dalam klasifikasi hipertensi derajat 3. Data tersebut menunjukkan masih baiknya angka kesehatan peserta.

Tabel 1. Jumlah peserta berdasarkan klasifikasi hipertensi

\begin{tabular}{lc}
\hline Klasifikasi Hipertensi & Jumlah (orang) \\
\hline $\begin{array}{l}\text { Normal } \\
\text { Systole } \leq 139 \text { dan/atau diastole } \leq 89\end{array}$ & 28 \\
& \\
Hipertensi Derajat 1 & 17 \\
Systole 140-159 dan/atau diastole & \\
$90-99$ & \\
Hipertensi Derajat 2 & \\
Systole 160-179 dan/atau diastole \\
100-109
\end{tabular}

Hasil pemeriksaan gula darah sewaktu peserta ditunjukkan pada Tabel 2. Tabel 2 menunjukkan bahwa dari 55 orang peserta yang melakukan pemeriksaan gula darah sewaktu, 43 orang memiliki kadar gula darah normal atau kurang dari $200 \mathrm{mg} /$ $\mathrm{dL}$ dan 12 orang memiliki kadar gula darah sewaktu yang lebih di atas normal atau $>200 \mathrm{mg} / \mathrm{dL}$. Data tersebut menunjukkan bahwa jumlah peserta lansia yang memeriksakan kadar gula darah sewaktunya dan hasilnya adalah gula darah lebih di atas normal hanya $21,8 \%$.

Tabel 2. Jumlah peserta berdasarkan kadar gula darah sewaktu

\begin{tabular}{lc}
\hline Kadar Gula Darah Sewaktu & Jumlah (orang) \\
\hline$\leq 200 \mathrm{mg} / \mathrm{dL}$ & 43 \\
$>200 \mathrm{mg} / \mathrm{dL}$ & 12 \\
\hline
\end{tabular}

\section{KESIMPULAN DAN SARAN}

Kegiatan pengabdian masyarakat ini sangat bermanfaat bagi lansia, mampu meningkatkan pengetahuan lansia.

\section{UCAPAN TERIMA KASIH}

Kami mengucapkan banyak terimakasih kepada Fakultas Vokasi Universitas Airlangga atas bantuan dana RKAT 2019 dan segenap warga RW VII Kelurahan Jagir Surabaya sehingga kegitan Pengabdian Masyarakat ini dapat berlangsung dengan baik. Penulis menyatakan tidak ada konflik kepentingan dengan pihak-pihak yang terkait dalam kegiatan pengabdian kepada masyarakat ini.

\section{DAFTAR PUSTAKA}

Imandiri, A. 2018. Pelayanan Kesehatan Secara Rutin Bagi Penduduk Lanjut Usia di Surabaya, Jawa Timur. Laporan Pengabdian Masyarakat PKM. Surabaya: Universitas Airlangga.

Henderson, A.J., Buchwald, D., Manson, S.M. 2006. Relationship of Medication Use to HealthRelated Quality of Life Among a Group of Older American. J Appl Gerontol Vol. 20(10). Pp 1-15.

Megari, K. 2013. Quality Of Life In Chronic Disease Patients. Health Psychol Vol. 1(27). Pp 141-148. 